\title{
Prevalence of Smoke-Free Car and Home Rules in Maine Before and After Passage of a Smoke-Free Vehicle Law, 2007-2010
}

Rebecca Murphy-Hoefer, PhD, MPH; Patrick Madden, MS; Dorean Maines, MS; Carol Coles

Suggested citation for this article: Murphy-Hoefer R, Madden P, Maines D, Coles C. Prevalence of Smoke-Free Car and Home Rules in Maine Before and After Passage of a Smoke-Free Vehicle Law, 2007-2010. Prev Chronic Dis 2014;11:130132. DOI: http://dx.doi.org/10.5888/pcd11.130132 捣.

PEER REVIEWED

\section{Abstract}

\section{Introduction}

This is the first study to examine the prevalence of self-reported smoke-free rules for private cars and homes before and after the passage of a smoke-free vehicle law.

\section{Methods}

Data were examined for 13,461 Maine adults aged 18 or older who participated in the Behavioral Risk Factor Surveillance System, a state-based telephone survey covering health topics. Self-reported smoke-free car and home rules, smoking behavior, and demographic variables of age, sex, education, income, and children in household were analyzed for prevalence before and after the state's smoke-free vehicle law was passed.

\section{Results}

Prevalence of smoke-free car and home rules was significantly higher after Maine's smoke-free vehicle law was passed in the state ( $P=.004$ for car rules and $P=.009$ for home rules). Variations in smoking rules differed by smoking and demographic variables. People with household incomes of less than $\$ 20,000$ saw an increase of $14.3 \%$ in smoke-free car rules; overall, those with annual incomes of less than $\$ 20,000$ and those with less than a high school education reported a lower prevalence of smoke-free car rules both before and after the law was passed than did people with higher incomes and higher education levels. The prevalence of smoke-free home rules after the law was implemented was higher among those with 4 or more years of college education than among those with lower levels of education $(P$ $=.02)$.

\section{Conclusion}

The prevalence of smoke-free car and home rules among Maine adults was significantly higher after the passage of a statewide smoke-free vehicle law. This apparent change in smoke-free rule prevalence may be indicative of changing social norms related to the unacceptability of secondhand smoke exposure.

\section{Introduction}

In the United States, 88 million nonsmokers were exposed to secondhand smoke in 2007 through 2008, including 32 million children aged 3 to 19 years (1). The involuntary exposure to tobacco smoke among infants and children increases risk of illness and premature death $(2,3)$. Given that small children breathe at a faster rate than adults, they are exposed to a greater quantity of air pollutants, including cigarette smoke (4). Smoking inside a small enclosed space such as a car is particularly dangerous because the concentration of pollutants from cigarette smoke can accumulate rapidly (5). Vehicle-related exposure to tobacco smoke causes infants to be lethargic (6) and young people to be twice as likely to develop asthma (7). Even with ventilation in vehicles, secondhand smoke from 1 or more cigarettes exceeds Environmental Protection Agency (EPA) limits (6,8). The 2006 Surgeon General's report concluded that there is no safe level of exposure to secondhand tobacco smoke (2). 
Although comprehensive state laws that ban smoking in public and private worksites, restaurants, and bars have increased, covering nearly half of US residents $(9,10)$, these laws do not protect children from exposure in private areas, such as vehicles and homes (4). In Maine, $22.8 \%$ of adults aged 18 or older currently smoke (9). As a result, 53\% of Maine high school students and $41 \%$ of middle school students are exposed to secondhand smoke at least once during any given week (11). The city of Bangor was the first and only locality in Maine to pass a smoke-free vehicle ordinance, which went into effect in 2007 (12). In January 2008, Maine passed a statewide law prohibiting smoking in a motor vehicle by the operator or a passenger whenever a person under the age of 16 years is present (13). This law went into effect on September 1, 2008.

Six states and 1 territory have passed laws prohibiting smoking in vehicles occupied by children (14). This is the first study to examine the prevalence of smoke-free car rules and smoke-free home rules before and after the passage of a smoke-free vehicle law. The objective of our study was to examine whether there was a difference in self-reported, smoke-free car and home rules after the passage of Maine's smoke-free vehicle law. The secondary purpose was to examine the characteristics of those who reported having such rules.

\section{Methods}

The Behavioral Risk Factor Surveillance System (BRFSS) is a cross-sectional state-based telephone health survey conducted through a random-digit-dialing methodology among persons aged 18 years or older (15). To study the prevalence of current cigarette smoking and the proportion of those with smoke-free car rules in Maine, BRFSS data from 2007 through 2010 were examined. Beginning in 2007, the Maine BRFSS partnered with the Maine Department of Health and Human Services, Maine Center for Disease Control and Prevention's Partnership for a Tobacco Free Maine program for a BRFSS split survey. In this split survey, the Centers for Disease Control and Prevention's core questions (called Part A) are the same in each survey, and the state adds questions (called Part B) that differ from state to state.

The sampling frame for Maine's Part B questions included only landline respondents from 2007 to 2010. The year 2007 is the first year data were collected for Maine's Part B questions, and no data on smoke-free rules from BRFSS exist before that time. A cellular telephone sample and changes to the weighting methods were introduced in 2011 and, because of these changes, data after 2010 are excluded from this analysis. The overall sample size for the Part B survey ranged from 2,648 in 2007 to 4,072 in 2010; Part B had a total sample size of 13,461 over the 4 years. Response rates ranged from a low of $47.8 \%$ in 2007 to a high of $58.3 \%$ in 2010.

To examine the impact of Maine's smoke-free vehicle law from 2007 through 2010, we separated BRFSS Part B surveys into 2 groups for analysis: 1) surveys collected in 2007 and 2) those collected after passage of the law from 2008 through 2010. The final sample sizes in this analysis were 2,648 respondents for the 2007 segment and 10,813 for the 2008 through 2010 segment.

Data from the BRFSS Part B surveys were analyzed, including demographic variables of age, sex, education, annual household income, number of children in the household, and smoking status. Differences between reported smoking rules before and after the law was passed were tested for significance overall and within each demographic category.

Participants were asked the following questions from the BRFSS core questions to determine cigarette smoking prevalence: "Have you smoked at least 100 cigarettes in your entire life?" and "Do you now smoke cigarettes every day, some days, or not at all?" Current smokers were defined as those who reported having smoked 100 or more cigarettes during their lifetime and who currently smoke every day or some days.

Data from the following BRFSS secondhand smoke survey items in Part B were examined: "Which of the following statements best describes the rules about smoking inside your car? No one is allowed to smoke inside your car, smoking is not allowed if children are in your car, or smoking is permitted anytime inside your car." and "Which of the following statements best describes the rules about smoking inside your home? No one is allowed to smoke anywhere inside your home, smoking is allowed in some places or at some times, smoking is permitted anywhere inside your home." All analyses and statistical tests were conducted using SUDAAN (Research Triangle Institute, Research Triangle Park, North Carolina), a statistical software package for the analysis of correlated data, including correlated data encountered in complex sample surveys like the BRFSS. Two-tailed $t$ tests for differences in proportions were conducted in SUDAAN to examine whether the policies of smoking inside cars or homes 1) changed after the passage of Maine's smoke-free vehicle law and 2) are significantly different within each of the demographic characteristics listed above.

\section{Results}

Among all participants in the BRFSS Part B survey from 2007 through $2010(\mathrm{n}=13,461)$, slightly less than half were male (48.2\%) (Table 1). The mean age of participants was 48.6 years, and the range of ages was from 18 to 97 years. The median annual household income among survey participants was between $\$ 35,000$ and $\$ 49,999$. Approximately 
one-third of the survey population (32.1\%) completed high school or had a general equivalency diploma (GED), and $6.6 \%$ had less than a high school education. One-quarter (25.7\%) attended some college or had a technical degree, and the remainder (35.6\%) had a college degree or higher. Close to two-fifths of participants (37.6\%) had at least 1 child in their household. Approximately half (49.3\%) of the survey population had smoked at least 100 cigarettes in their lifetime. Overall, at the time of the surveys, more than four-fifths (82.4\%) did not smoke, and $17.6 \%$ were current smokers. All demographics showed nonsignificant change between the 2007 survey and the 2008 through 2010 surveys at $P<.05$.

\section{Smoke-free car rules}

Table 2 shows the relative change in smoke-free car rules by various demographic factors after the smoke-free vehicle law was passed. Overall, $78.8 \%$ of Maine adults aged 18 years or older reported a smoke-free car rule after the smokefree vehicle law was passed. This is a significant change from before the law, when 74.9 of adults reported having a smoke-free car rule $(P=.004)$. The percentage of adults reporting no rule (ie, smoking is allowed anytime inside car) was significantly lower after the law was in place (from $7.9 \%$ before the law to $5.1 \%$ after the law, $P<.001$ ). Examining the results by year shows no significant difference between reported rules in the 3 years after the law was implemented (78.6\% in 2008, $78.1 \%$ in 2009, and 79.8\% in 2010), an indication that the prevalence of smoke-free car rules was consistent in the 3 years following passage of the law.

By demographic characteristics (Table 2), significant changes in reported smoke-free car rules occurred after the law was passed compared with before the law was passed among women (prevalence was $6.2 \%$ higher, $P=.005$ ), high school graduates and those with a GED ( $8.3 \%$ increase, $P=.04)$, and those with children in their household (11.6\% increase, $P=.002)$. Although adults with annual household incomes of less than $\$ 20$,ooo had the highest percentage increase (14.2\%) in smoke-free rules after the law was passed compared with before the law, both those with incomes of less than $\$ 20,000$ and those with less than a high school education had a lower prevalence of smoke-free car rules before and after the law was passed than did those with incomes above $\$ 20,000$ and those with a high school education or better. Only $64.5 \%$ of adults with less than a high school education reported having a smoke-free car rule after the law was implemented, but $88.2 \%$ of college graduates reported having such a rule. Among adults with household incomes of less than $\$ 20,000,65.0 \%$ had a smoke-free car rule after the law was implemented, compared with $88.8 \%$ of those with annual household incomes of $\$ 75,000$ or more.

Both before and after passage of the law, nonsmokers were more likely to report having a voluntary smoke-free car rule (86.4\% before and $88.5 \%$ after) than were current smokers $(21.8 \%$ and $26.9 \%)(P<.001)$. Although not significant, this $23.3 \%$ relative increase for current smokers is the largest for any demographic groups; however, current smoker sample sizes in the BRFSS are smaller than many other demographic groups, which may contribute to the lack of statistical power for the current smoker segment. Among adults who never smoked, 9 in 10 reported having a smokefree car rule after the law was implemented.

Among respondents who had children in their household and who reported not allowing smoking in their car, the prevalence was significantly higher after the law was passed $(69.2 \%$ before and $77.2 \%$ after, $P=.002)$ (Table 2$)$. In addition, the percentage of those who allowed smoking any time in the car was significantly lower (reduced by nearly half) after implementation of the law. Only $3.7 \%$ of adults with children in their household allowed smoking anytime in their cars after the law was implemented compared with $6.8 \%$ before the law was implemented $(P=.04)$. Although not significant, there was an increase in the percentage of current smokers with children in the household who reported having a smoke-free car rule, from $19.2 \%$ before the law was passed to $30.7 \%$ after the law was passed; this $59.9 \%$ relative increase is the largest among all of the demographic groups. By contrast, adult smokers without children showed no significant change in the percentage who reported having rules about not smoking in their cars after the law went into effect (23.8\% before; $24.0 \%$ after).

A secondary analysis comparing the period before the law's implementation and the period afterward (ie, comparing January 2007 through August 2008 with September 2008 through December 2010) revealed that smokers with children in their household reported significantly higher levels of smoke-free car rules after the law was implemented $(31.5 \%)$ than before implementation (22.0\%) $(P=.03)$, a percentage increase of approximately $43 \%$ (data not shown).

\section{Smoke-free home rules}

The percentage of respondents reporting having a smoke-free home rule was significantly higher after passage of the smoke-free car law, 83.1\%, than before, 79.9\%, $P=.009$ (Table 3). The prevalence of smoke-free home rules after the law was implemented was higher among those with 4 or more years of college education than among those with lower levels of education $(P=.02)$.

\section{Discussion}

Our study shows that the prevalence of smoke-free car and home rules among Maine adults was significantly higher after the passage of its statewide smoke-free vehicle law. The fact that this change in smoke-free rule prevalence 
coincided with the passage of a smoke-free vehicle law may be indicative of changing social norms related to the unacceptability of secondhand smoke exposure among Maine adults. The link between public smoke-free laws and voluntary smoke-free rules is a possible explanation for the change that was observed in our study (16).

The intent to protect children is demonstrated by the increase in smoke-free car rules after the passage of the law. Current smokers with children in their household reported an increase in smoke-free rules after the law was passed compared with almost no increase for smokers without children in their household. However, disparities exist as seen in the literature $(17,18)$. Another smoke-free vehicle study found misperceptions among low-income adults regarding the efficacy of keeping windows down to avoid the hazards of exposure to secondhand smoke (19).

Although smoke-free car rules increased in Maine, more work remains to be done. Among all participants surveyed from 2007 through 2010, 16.4\% still allowed smoking when children were not present. This is problematic because the residues from tobacco smoke components stay on vehicle surfaces. One study found that used vehicles owned previously by smokers had significantly higher levels of nicotine in the air, dust, and vehicle surfaces than vehicles owned by nonsmokers (20). Another study detected the interaction of cigarette smoke and vehicle engine emissions forming carcinogenic tobacco-specific nitrosamines (21). This finding is cause for action given the harm to infants and children because of their contact with surfaces and quicker respiration (4).

Children are among the most exposed groups to secondhand smoke (1). Our study also reviewed smoke-free home policies during the same period, because children are more likely than nonsmoking adults to live with someone who smokes. Concern over a potential increase in smoking in homes after the implementation of smoke-free laws in public places has been discussed and found to be unwarranted (16). Our results also counter this concern given that voluntary smoke-free home policies also increased significantly after Maine's law was implemented. Because smoke-free home rules are voluntary, they serve as an indicator of public attitudes and social norms, as well as support for smoke-free indoor environment policies $(16,22-24)$. Other studies found that smoke-free home policies reduce smoking initiation among young people and help smokers quit (2). The implications for public health are immense; childhood exposure to secondhand smoke increases the risk of illness and premature death $(2,3)$, including respiratory diseases (2); sudden infant death syndrome (SIDS) (2); cancer as an adult (25); higher lead blood levels (26); and attentiondeficit/hyperactivity disorder, learning disabilities, and conduct disorders (27). Among US children, secondhand smoke exposure costs $\$ 4.98$ billion in annual health care expenditures (28).

Possible explanations for the positive outcomes of Maine's state law include the comprehensive programs conducted throughout the state. In particular, to educate the public about the law in Maine and to raise awareness about the effects of secondhand smoke exposure, the Partnership for a Tobacco-Free Maine implemented a statewide health communication campaign titled, "Wherever You Live and Breathe, Go Smoke-Free." The campaign included the use of television and radio. The media campaign was on air from February 14, 2008, through November 30, 2008. Furthermore, Maine has strong smoke-free workplace and public place laws that contain few exceptions or loopholes. Maine does not prevent localities from implementing policies stronger than the state laws, and many localities have done so. Support for the current law may continue because research shows that more favorable attitudes toward smoke -free laws exist as a result of advances in the scope of smoke-free indoor environment policies $(16,29)$, including policies related to smoking in vehicles (30).

A limitation of this study is that estimates for cigarette smoking and voluntary smoke-free rules are based on selfreports and are not validated with biochemical tests. However, self-reported data on current smoking status have high validity (15). Another limitation is that the Maine BRFSS survey item includes smoke-free rules for cars, not all types of vehicles such as sport-utility vehicles, minivans, and trucks. As a result, the current prevalence data may be a conservative number.

The smoke-free car law is part of a comprehensive tobacco control program that includes multiple interventions: state and community, health communication, and tobacco cessation. Therefore, it is difficult to separate the effects of 1 aspect of a comprehensive program from all other aspects. In particular, the statewide "Wherever You Live and Breathe, Go Smoke-Free" campaign may have contributed to the increase in voluntary smoke-free car and home rules. Other factors that may account for the increase in voluntary home rules could be the federal cigarette tax that went into effect in 2009 and the trend toward lower smoking prevalence in Maine.

Because of the limited availability of data, equivalent survey measures between 2007 and 2010 were not available to make comparisons with an analogous state that does not have a smoke-free car law; however, we found 2 data sources that may provide support for our findings. Vermont has similar statewide laws prohibiting smoking in public places and worksites, but not a smoke-free car law. In 2007 Maine and Vermont had a statistically equivalent prevalence of voluntary smoke-free home rules, $75.4 \%$ in Vermont and $76 \%$ in Maine according to the Tobacco Use Supplement to the Current Population Survey (TUS-CPS) (31). In 2010, Maine had a significantly higher prevalence of voluntary smoke-free home rules than Vermont (Maine $84.4 \%$ vs Vermont 80.6\%), according to the National Adult Tobacco Use Survey (2010 TUS-CPS data were not available when we wrote this article) (9). It is a limitation that these data are 
from 2 different sources; however, these were the only data available to provide additional insight. These data sources as well as year intervals are the same as those featured in the Centers for Disease Control and Prevention's Tobacco Control State Highlights 2010 (9,31). There are limited data about smoke-free vehicle rules and consistent survey questions. Consideration of smoke-free vehicle rule measures in surveillance surveys are needed to conduct future studies to compare demographics and smoke-free vehicle rules among states.

Although exposure to tobacco smoke has declined in the United States, much remains to be done to reduce the disparities in exposure, especially among young people. In addition to protecting children, smoke-free vehicle laws may also reduce the negative health consequences experienced by other vulnerable populations and all nonsmokers given that there is no safe level of exposure to secondhand smoke (2). States with comprehensive smoke-free indoor policies that include worksites such as restaurants and bars should consider extending them to include private areas such as vehicles. Smoke-free vehicle laws may strengthen support for the protection of populations from exposure to secondhand smoke, increase the population's knowledge about the negative effects of secondhand smoke, increase smoke-free norms, and assist in reducing tobacco use.

\section{Acknowledgments}

Rebecca Murphy-Hofer and Patrick Madden serve as evaluation contractors for the Partnership for a Tobacco-Free Maine through a contract with the University of New England.

\section{Author Information}

Corresponding Author: Rebecca L. Murphy-Hoefer, PhD, MPH, School of Community and Population Health, University of New England, 716 Stevens Ave, Portland, ME 04103. E-mail: murphy.rebecca@ymail.com.

Author affiliations: Patrick Madden, Market Decisions, Portland, Maine; Dorean Maines, Carol Coles, Partnership for a Tobacco-Free Maine, Augusta, Maine.

\section{References}

1. Centers for Disease Control and Prevention. Vital signs: nonsmokers' exposure to secondhand smoke - United States, 1999-2008. MMWR Morb Mortal Wkly Rep 2010;59(35):1141-6. PubMed 橉

2. The health consequences of involuntary exposure to tobacco smoke: a report of the Surgeon General. Atlanta (GA): US Department of Health and Human Services, Centers for Disease Control and Prevention, Coordinating Center for Health Promotion, National Center for Chronic Disease Prevention and Health Promotion, Office on Smoking and Health; 2006.

3. Gibbs FA, Tong VT, Farr SL, Dietz PM, Babb S. Smoke-free-home rules among women with infants, 2004-2008. Prev Chronic Dis 2012;9:120108. Accessed November 12, 2012. CrossRef 国 PubMed 国

4. Weisman SR. Kids, cars and cigarettes: policy options for smoke-free vehicles. St Paul (MN): Public Health Law Center; 2010.

5. Halterman JS, Fagnano M, Conn KM, Szilagyi PG. Do parents of urban children with persistent asthma ban

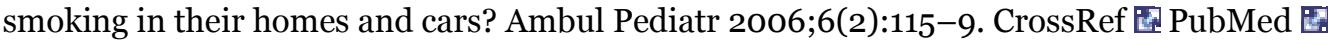

6. Rees VW, Connolly GN. Measuring air quality to protect children from secondhand smoke in cars. Am J Prev Med

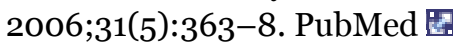

7. Sly PD, Deverell M, Kusel MM, Holt PG. Exposure to environmental tobacco smoke in cars increases the risk of persistent wheeze in adolescents. Med $\mathrm{J}$ Aust 2007;186(6):322. PubMed 圈

8. Sendzik T, Fong G, Travers M, Hyland A. An experimental investigation of tobacco smoke pollution in cars. Nicotine Tob Res 2009;11(6):627-34. CrossRef 国 PubMed 运

9. Tobacco control state highlights 2012. Atlanta (GA): US Department of Health and Human Services, Centers for Disease Control and Prevention, National Center for Chronic Disease Prevention and Health Promotion, Office on Smoking and Health; 2013.

10. Centers for Disease Control and Prevention. State smoke-free laws for worksites, restaurants, and bars - United States, 2000-2010. MMWR Morb Mortal Wkly Rep 2011;60(15):472-5. PubMed 圈

11. Healthy Maine Partnerships. Tobacco facts. http://www.healthymainepartnerships.org/documents/TobaccoFacts.pdf. Accessed October 15, 2012.

12. Code of the City of Bangor, Article IX. Sections 291-70 and 291-71.

13. MRSA $22 \S 1549$. 
14. Americans for Nonsmokers' Rights. Smokerfree cars. http://www.no-smoke.org/learnmore.php?id=616. Accessed August 3, 2013.

15. Nelson DE, Holtzman D, Bolen J, Stanwyck CA, Mack KA. Reliability and validity of measures from the Behavioral Risk Factor Surveillance System (BRFSS). Soz Praventivmed 2001;46(Suppl 1):S3-42. PubMed 圈

16. Borland R, Yong HH, Cummings KM, Hyland A, Anderson S, Fong GT. Determinants and consequences of smoke -free homes: findings from the International Tobacco Control (ITC) Four Country Survey. Tob Control 2006;15 (Suppl 3):iii42-50. PubMed 圈

17. Mills AL, White MM, Pierce JP, Messer K. Home smoking bans among U.S. households with children and smokers. Opportunities for intervention. Am J Prev Med 2011;41(6):559-65. CrossRef 圈 PubMed 圈

18. Patel V, Thomson G, Wilson N. Objective measurement of area differences in 'private' smoking behaviour: observing smoking in vehicles. Tob Control 2013;22(2):130-5. CrossRef 圈 PubMed 圈

19. Kegler MC, Escoffery C, Butler S. A qualitative study on establishing and enforcing smoking rules in family cars. Nicotine Tob Res 2008;10(3):493-7. CrossRef 圈 PubMed 圈

20. Matt GE, Quintana PJ, Hovell MF, Chatfield D, Ma DS, Romero R, et al. Residual tobacco smoke pollution in used cars for sale: air, dust, and surfaces. Nicotine Tob Res 2008;10(9):1467-75. CrossRef \&ubMed 国

21. Sleimana M, Gundela LA, Pankowb JF, Jacob P, Singera BC, Destaillats H. Formation of carcinogens indoors by surface-mediated reactions of nicotine with nitrous acid, leading to potential thirdhand smoke hazards.

Proceedings of the National Academy of Sciences of the United States of America.

http://www.pnas.org/content/early/2010/02/04/0912820107.full.pdf+html?sid=a9fa8602-2b11-433d-a6cd-

173e01d3e409. Accessed November 12, 2012.

22. Fong GT, Hyland A, Borland R, Hammond D, Hastings G, McNeill A, et al. Reductions in tobacco smoke pollution and increases in support for smoke-free public places following the implementation of comprehensive smoke-free workplace legislation in the Republic of Ireland: f\&inodot;ndings from the ITC Ireland/UK Survey. Tob Control 2006;15(Suppl 3):iii51-8. CrossRef 国 PubMed 国

23. Akhtar PC, Haw SJ, Currie DB, Zachary R, Currie CE. Smoking restrictions in the home and secondhand smoke exposure among primary schoolchildren before and after introduction of the Scottish smoke-free legislation. Tob Control 2009;18(5):409-15. CrossRef 国 PubMed 圈

24. Centers for Disease Control and Prevention. State-specific prevalence of smoke-free home rules - United States 1992-2003. MMWR Morb Mortal Wkly Rep 2007;56(20):501-4. PubMed 圈

25. Environmental tobacco smoke: a hazard to children. American Academy of Pediatrics Committee on Environmental Health. Pediatrics 1997;99(4):639-42. CrossRef 国 PubMed 圈

26. Apostolou A, Garcia-Esquinas E, Fadrowski JJ, McClain P, Weaver VM, Navas-Acien A. Secondhand tobacco smoke: a source of lead exposure in US children and adolescents. Am J Public Health 2012;102(4):714-22. CrossRef 圈 PubMed 圈

27. Kabir Z, Connolly GN, Alpert HR. Secondhand smoke exposure and neurobehavioral disorders among children in the United States. Pediatrics 2011;128(2):263-70. CrossRef 圈 PubMed 圈

28. Guilfoyle J. Toll of tobacco in the United States of America. Campaign for Tobacco Free Kids, 2011. http://www.tobaccofreekids.org/research/factsheets/pdf/o072.pdf. Accessed November 12, 2012.

29. Hyland A, Higbee C, Borland R, Travers MJ, Hastings G, Fong GT, et al. Attitudes and beliefs about secondhand smoke and smoke-free policies in four countries: Findings from the International Tobacco Control Four Country Survey. Nicotine Tob Res 2009;11(6):642-9. CrossRef 圈 PubMed 恩

30. King BA, Dube SR, Homa DM. Smoke-free rules and secondhand smoke exposure in homes and vehicles among US adults, 2009-2010. Prev Chronic Dis 2013;10:120218. . Accessed May 21, 2013. CrossRef 圈 PubMed 圈

31. Tobacco control state highlights, 2010. Atlanta (GA): US Department of Health and Human Services, Centers for Disease Control and Prevention, National Center for Chronic Disease Prevention and Health Promotion, Office on Smoking and Health, 2010.

\section{Tables}

Table 1. Characteristics of Respondents to Maine's Behavioral Risk Factor Surveillance System (BRFSS) Part B Before and After Passage of a Law Prohibiting Smoking in Vehicles, 2007-2010a 
Preventing Chronic Disease | Prevalence of Smoke-Free Car and Home Rules in Maine B... Page 7 of 10

\begin{tabular}{|c|c|c|c|c|c|c|}
\hline \multirow[b]{2}{*}{ Characteristic } & \multicolumn{2}{|c|}{ Before Law (2007) } & \multicolumn{2}{|c|}{ After Law (2008-2010)b } & \multicolumn{2}{|c|}{ Combined 2007-2010 } \\
\hline & $\begin{array}{c}\text { Unweighted } \\
\text { Sample }(\mathrm{n}= \\
2,648) \mathrm{c}\end{array}$ & $\begin{array}{c}\text { Weighted } \\
\% d\end{array}$ & $\begin{array}{c}\text { Unweighted } \\
\text { Sample }(\mathrm{n}= \\
10,813) \mathrm{c}\end{array}$ & $\begin{array}{c}\text { Weighted } \\
\% \text { od }\end{array}$ & $\begin{array}{c}\text { Unweighted } \\
\text { Sample }(n= \\
13,461) c\end{array}$ & $\begin{array}{c}\text { Weighted } \\
\% \text { od }\end{array}$ \\
\hline \multicolumn{7}{|l|}{ Sex } \\
\hline Male & 964 & 48.2 & 4,206 & 48.2 & 5,170 & 48.2 \\
\hline Female & 1,684 & 51.8 & 6,607 & 51.8 & 8,291 & 51.8 \\
\hline \multicolumn{7}{|l|}{ Age, $y$} \\
\hline $18-24$ & 76 & 11.9 & 295 & 9.1 & 371 & 9.8 \\
\hline $25-34$ & 243 & 13.9 & 692 & 14.3 & 935 & 14.2 \\
\hline $35-44$ & 417 & 18.2 & 1,453 & 19.4 & 1,870 & 19.1 \\
\hline $45-54$ & 590 & 20.7 & 2,321 & 20.8 & 2,911 & 20.8 \\
\hline $55-64$ & 606 & 16.2 & 2,620 & 16.9 & 3,226 & 16.8 \\
\hline$\geq 65$ & 700 & 19.0 & 3,355 & 19.5 & 4,055 & 19.4 \\
\hline \multicolumn{7}{|l|}{ Education } \\
\hline $\begin{array}{l}\text { Less than high } \\
\text { school diploma }\end{array}$ & 189 & 7.6 & 696 & 6.3 & 885 & 6.6 \\
\hline $\begin{array}{l}\text { High school } \\
\text { graduate or GED }\end{array}$ & 804 & 30.5 & 3,512 & 32.6 & 4,316 & 32.1 \\
\hline $\begin{array}{l}\text { Some college or } \\
\text { technical school }\end{array}$ & 684 & 27.3 & 2,659 & 25.1 & 3,343 & 25.7 \\
\hline $\begin{array}{l}\text { College } 4 \text { years or } \\
\text { more }\end{array}$ & 968 & 34.6 & 3,933 & 36.0 & 4,901 & 35.6 \\
\hline \multicolumn{7}{|c|}{ Annual household income, \$ } \\
\hline$<20,000$ & 454 & 16.3 & 2,002 & 16.6 & 2,456 & 16.5 \\
\hline $20,000-34,999$ & 524 & 22.2 & 2,129 & 20.1 & 2,653 & 20.6 \\
\hline $35,000-49,999$ & 412 & 17.8 & 1,650 & 17.5 & 2,062 & 17.6 \\
\hline $50,000-74,999$ & 408 & 18.3 & 1,618 & 18.8 & 2,026 & 18.7 \\
\hline$\geq 75,000$ & 519 & 25.3 & 2,205 & 27.0 & 2,724 & 26.6 \\
\hline \multicolumn{7}{|c|}{ Children in household } \\
\hline Yes & 709 & 35.6 & 2,743 & 38.3 & 3,452 & 37.6 \\
\hline No & 1,936 & 64.4 & 8,061 & 61.7 & 9,997 & 62.4 \\
\hline \multicolumn{7}{|c|}{ Current smoking status } \\
\hline Current smoker & 475 & 19.0 & 1,684 & 17.1 & 2,159 & 17.6 \\
\hline Nonsmoker & 2,160 & 81.0 & 9,064 & 82.9 & 11,224 & 82.4 \\
\hline
\end{tabular}

Abbreviations: BRFSS, Behavioral Risk Factor Surveillance System; GED, general equivalency diploma.

a Part B is survey questions added by the state to the core BRFSS survey questions.

b No significant differences in demographics from before to after the law was enacted at $P<.05$.

c Missing values are not included.

d Percentage of valid responses among respondents in each category.

Table 2. Adults Aged 18 or Older Reporting Smoke-Free Car Rule (No One Is Allowed to Smoke Inside the Car) Before and After Passage of a Law 
Preventing Chronic Disease | Prevalence of Smoke-Free Car and Home Rules in Maine B... Page 8 of 10

Prohibiting Smoking in Vehicles, Behavioral Risk Factor Surveillance System, Maine, 2007-2010

\begin{tabular}{|c|c|c|c|c|c|c|}
\hline \multirow[b]{2}{*}{ Characteristic } & \multicolumn{2}{|c|}{ Before Law (2007) } & \multicolumn{2}{|c|}{ After Law (2008-2010) } & \multirow[b]{2}{*}{$\begin{array}{c}\% \\
\text { Change }\end{array}$} & \multirow[b]{2}{*}{$\begin{array}{c}P \\
\text { Valueb }\end{array}$} \\
\hline & $\begin{array}{l}\text { Unweighted } \\
\text { Sample Sizea }\end{array}$ & $\begin{array}{l}\text { \% With } \\
\text { Rule }\end{array}$ & $\begin{array}{l}\text { Unweighted } \\
\text { Sample Sizea }\end{array}$ & $\begin{array}{l}\text { \% With } \\
\text { Rule }\end{array}$ & & \\
\hline Overall & 2,399 & 74.9 & 9,960 & 78.8 & 5.2 & .004 \\
\hline \multicolumn{7}{|l|}{ Year } \\
\hline 2007 & 2,399 & 74.9 & & NA & & \multirow{5}{*}{ NA } \\
\hline 2008 & & & 2,498 & 78.6 & & \\
\hline 2009 & & NA & 3,697 & 78.1 & & \\
\hline 2010 & & & 3,765 & 79.8 & & \\
\hline \multicolumn{6}{|l|}{ Sex } & \\
\hline Male & 867 & 72.6 & 3,876 & 75.6 & 4.1 & .17 \\
\hline Female & 1,532 & 77.0 & 6,084 & 81.8 & 6.2 & .005 \\
\hline \multicolumn{7}{|l|}{ Age, y } \\
\hline $18-24$ & 66 & 56.2 & 255 & 63.7 & 13.3 & .33 \\
\hline $25-34$ & 218 & 74.6 & 653 & 76.6 & 2.7 & .61 \\
\hline $35-44$ & 381 & 70.5 & 1,365 & 75.6 & 7.2 & .09 \\
\hline $45-54$ & 541 & 75.1 & 2,140 & 77.8 & 3.6 & .28 \\
\hline $55-64$ & 558 & 80.4 & 2,448 & 81.7 & 1.6 & .52 \\
\hline$\geq 65$ & 622 & 85.5 & 3,033 & 88.9 & 4.0 & .05 \\
\hline \multicolumn{7}{|l|}{ Education } \\
\hline Less than high school diploma & 149 & 56.9 & 563 & 64.5 & 13.4 & .30 \\
\hline High school graduate or GED & 721 & 65.6 & 3,162 & 71.1 & 8.4 & .04 \\
\hline Some college or tech school & 614 & 76.3 & 2,468 & 77.8 & 2.0 & .56 \\
\hline College 4 years or more & 913 & 85.0 & 3,754 & 88.2 & 3.8 & .05 \\
\hline \multicolumn{7}{|l|}{ Annual household income, $\$$} \\
\hline$<20,000$ & 373 & 56.9 & 1,695 & 65.0 & 14.2 & .05 \\
\hline $20,000-34,999$ & 487 & 70.9 & 1,984 & 73.8 & 4.1 & .41 \\
\hline $35,000-49,999$ & 387 & 74.5 & 1,576 & 75.2 & 0.9 & .83 \\
\hline $50,000-74,999$ & 385 & 77.0 & 1,547 & 81.6 & 6.0 & .16 \\
\hline$\geq 75,000$ & 491 & 86.4 & 2,113 & 88.8 & 2.8 & .27 \\
\hline \multicolumn{7}{|l|}{ Children in household } \\
\hline Yes & 639 & 69.2 & 2,577 & 77.2 & 11.6 & .002 \\
\hline No & 1,758 & 78.0 & 7,375 & 79.8 & 2.3 & .24 \\
\hline \multicolumn{7}{|l|}{ Current smoking status } \\
\hline Current smoker & 398 & 21.8 & 1,454 & 26.9 & 23.4 & .14 \\
\hline Nonsmoker & 1,991 & 86.4 & 8,454 & 88.5 & 2.4 & .09 \\
\hline \multicolumn{7}{|c|}{ Smoking status and children in household } \\
\hline $\begin{array}{l}\text { Current smoker and children } \\
\text { in household }\end{array}$ & 132 & 19.2 & 457 & 30.7 & 59.9 & .05 \\
\hline
\end{tabular}


Preventing Chronic Disease | Prevalence of Smoke-Free Car and Home Rules in Maine B... Page 9 of 10

\begin{tabular}{|c|c|c|c|c|c|c|}
\hline \multirow[b]{2}{*}{ Characteristic } & \multicolumn{2}{|c|}{ Before Law (2007) } & \multicolumn{2}{|c|}{ After Law (2008-2010) } & \multirow[b]{2}{*}{$\begin{array}{c}\% \\
\text { Change }\end{array}$} & \multirow[b]{2}{*}{$\begin{array}{c}P \\
\text { Valueb }\end{array}$} \\
\hline & $\begin{array}{l}\text { Unweighted } \\
\text { Sample Sizea }\end{array}$ & $\begin{array}{l}\text { \% With } \\
\text { Rule }\end{array}$ & $\begin{array}{l}\text { Unweighted } \\
\text { Sample Sizea }\end{array}$ & $\begin{array}{l}\text { \% With } \\
\text { Rule }\end{array}$ & & \\
\hline $\begin{array}{l}\text { Current smoker and no } \\
\text { children in household }\end{array}$ & 266 & 23.8 & 997 & 24.0 & 0.8 & .84 \\
\hline
\end{tabular}

Abbreviations: NA, not applicable; GED, general equivalency diploma.

a Missing values are not included.

b Two-tailed $t$ tests for differences in proportions.

Table 3. Percentage of Adults Aged 18 or Older Reporting Smoke-Free Home Rule (Smoking Is Not Allowed Anywhere Inside the Home) Before and After Passage of a Law Prohibiting Smoking in Vehicles, Maine, 2007-2010

\begin{tabular}{|c|c|c|c|c|c|c|}
\hline \multirow[b]{2}{*}{ Characteristic } & \multicolumn{2}{|c|}{ Before Law (2007) } & \multicolumn{2}{|c|}{ After Law (2008-2010) } & \multirow[b]{2}{*}{$\begin{array}{c}\% \\
\text { Change }\end{array}$} & \multirow[b]{2}{*}{$\begin{array}{c}P \\
\text { Valueb }\end{array}$} \\
\hline & $\begin{array}{l}\text { Unweighted } \\
\text { Sample Sizea }\end{array}$ & $\begin{array}{l}\text { \% With } \\
\text { Rule }\end{array}$ & $\begin{array}{l}\text { Unweighted } \\
\text { Sample Sizea }\end{array}$ & $\begin{array}{l}\text { \% With } \\
\text { Rule }\end{array}$ & & \\
\hline Overall & 2,488 & 79.9 & 10,277 & 83.1 & 4.0 & .009 \\
\hline \multicolumn{7}{|l|}{ Year } \\
\hline 2007 & 2,488 & 79.9 & & NA & & \multirow{5}{*}{ NA } \\
\hline 2008 & & & 2,590 & 83.0 & & \\
\hline 2009 & & NA & 3,821 & 83.3 & & \\
\hline 2010 & & & 3,866 & 82.9 & & \\
\hline \multicolumn{6}{|l|}{ Sex } & \\
\hline Male & 899 & 79.0 & 3,973 & 82.0 & 3.8 & .11 \\
\hline Female & 1,589 & 80.7 & 6,304 & 84.1 & 4.2 & .04 \\
\hline \multicolumn{7}{|l|}{ Age, y } \\
\hline $18-24$ & 72 & 73.9 & 277 & 77.4 & 4.7 & .62 \\
\hline $25-34$ & 225 & 85.9 & 660 & 88.2 & 2.7 & .45 \\
\hline $35-44$ & 390 & 80.6 & 1,391 & 85.3 & 5.8 & .07 \\
\hline $45-54$ & 552 & 80.1 & 2,202 & 81.7 & 2.0 & .47 \\
\hline $55-64$ & 577 & 78.5 & 2,510 & 81.7 & 4.1 & .14 \\
\hline$\geq 65$ & 658 & 78.9 & 3,169 & 82.5 & 4.6 & .08 \\
\hline \multicolumn{7}{|l|}{ Education } \\
\hline $\begin{array}{l}\text { Less than high school } \\
\text { graduate }\end{array}$ & 175 & 60.7 & 635 & 65.4 & 7.7 & .49 \\
\hline High school graduate or GED & 748 & 75.4 & 3,300 & 76.2 & 1.1 & .74 \\
\hline Some college or tech school & 637 & 79.4 & 2,547 & 84.3 & 6.2 & .05 \\
\hline College 4 years or more & 925 & 88.1 & 3,782 & 91.2 & 3.5 & .02 \\
\hline \multicolumn{7}{|l|}{ Annual household income, \$ } \\
\hline$<20,000$ & 417 & 65.8 & 1,892 & 68.3 & 3.8 & .50 \\
\hline $20,000-34,999$ & 498 & 74.7 & 2,019 & 78.9 & 5.6 & .21 \\
\hline $35,000-49,999$ & 393 & 79.9 & 1,595 & 81.0 & 1.4 & .70 \\
\hline $50,000-74,999$ & 390 & 82.5 & 1,550 & 90.0 & 9.1 & .009 \\
\hline & & & & & & \\
\hline
\end{tabular}


Preventing Chronic Disease | Prevalence of Smoke-Free Car and Home Rules in Maine... Page 10 of 10

\begin{tabular}{|c|c|c|c|c|c|c|}
\hline \multirow[b]{2}{*}{ Characteristic } & \multicolumn{2}{|c|}{ Before Law (2007) } & \multicolumn{2}{|c|}{ After Law (2008-2010) } & \multirow[b]{2}{*}{$\begin{array}{c}\% \\
\text { Change }\end{array}$} & \multirow[b]{2}{*}{$\begin{array}{c}P \\
\text { Valueb }\end{array}$} \\
\hline & $\begin{array}{l}\text { Unweighted } \\
\text { Sample Sizea }\end{array}$ & $\begin{array}{l}\text { \% With } \\
\text { Rule }\end{array}$ & $\begin{array}{l}\text { Unweighted } \\
\text { Sample Sizea }\end{array}$ & $\begin{array}{l}\text { \% With } \\
\text { Rule }\end{array}$ & & \\
\hline$\geq 75,000$ & 491 & 90.6 & 2,112 & 91.8 & 1.3 & .48 \\
\hline \multicolumn{7}{|l|}{ Children in household } \\
\hline Yes & 648 & 85.7 & 2,619 & 88.5 & 3.3 & .18 \\
\hline No & 1,838 & 76.8 & 7,650 & 79.7 & 3.8 & .05 \\
\hline \multicolumn{7}{|l|}{ Current smoking status } \\
\hline Current smoker & 433 & 50.5 & 1,571 & 54.9 & 8.7 & .24 \\
\hline Nonsmoker & 2,043 & 86.5 & 8,651 & 88.7 & 2.5 & .08 \\
\hline \multicolumn{7}{|c|}{ Smoking status and children in household } \\
\hline $\begin{array}{l}\text { Current smoker and children } \\
\text { in household }\end{array}$ & 139 & 66.5 & 479 & 71.4 & 7.4 & .44 \\
\hline $\begin{array}{l}\text { Current smoker and no } \\
\text { children in household }\end{array}$ & 294 & 38.7 & 1,092 & 42.9 & 10.9 & .36 \\
\hline
\end{tabular}

Abbreviations: BRFSS, Behavioral Risk Factor Surveillance System; GED, general equivalency diploma.

a Missing values are not included.

b Two-tailed $t$ tests for differences in proportions.

The opinions expressed by authors contributing to this journal do not necessarily reflect the opinions of the U.S.

Department of Health and Human Services, the Public Health Service, the Centers for Disease Control and Prevention, or the authors' affiliated institutions.

The RIS file format is a text file containing bibliographic citations. These files are best suited for import into

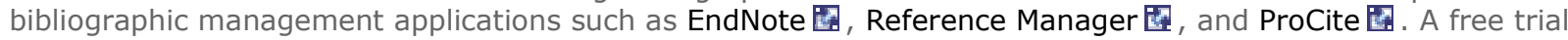
download is available at each application's web site.

For Questions About This Article Contact pcdeditor@cdc.gov

Page last reviewed: January 16, 2014

Page last updated: January 16, 2014

Content source: National Center for Chronic Disease Prevention and Health Promotion

Centers for Disease Control and Prevention 1600 Clifton Rd. Atlanta, GA 30333, USA

80o-CDC-INFO (800-232-4636) TTY: (888) 232-6348 - Contact CDC-INFO

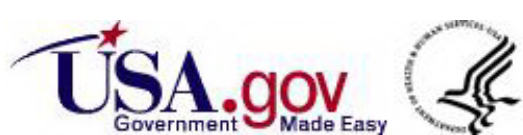

